\title{
Defects in lens fiber differentiation are linked to c-mos overexpression in transgenic mice
}

\author{
Jaspal S. Khillan, ${ }^{1}$ Marianne K. Oskarsson, ${ }^{3}$ Friedrich Propst, ${ }^{3}$ Toichiro Kuwabara, ${ }^{2}$ George F. Vande \\ Woude, $^{3}$ and Heiner Westphal ${ }^{1}$ \\ ${ }^{1}$ Laboratory of Molecular Genetics, National Institute of Child Health and Human Development, and ${ }^{2}$ Laboratory of \\ Ophthalmic Pathology, National Eye Institue, National Institutes of Health, Bethesda, Maryland 20892 USA; ${ }^{3}$ Molecular \\ Mechanisms of Carcinogenesis Laboratory, BRI-Basic Research Program, NCI-Frederick Cancer Research Facility, Frederick, \\ Maryland 21701 USA
}

\begin{abstract}
We describe three strains of transgenic mice derived by embryo microinjection of DNA consisting of a long terminal repeat (LTR) of Moloney murine sarcoma virus (Mo-MSV) linked to the murine c-mos coding sequences. Southern analysis of the genomic DNA of these strains suggested that in each case the transgene had integrated at a different chromosomal location. The strains were characterized by dominant changes in secondary lens fiber differentiation. Shortly after birth, insufficient elongation of differentiating lens fibers and lack of basement membrane secretion resulted in breakdown of the posterior lens capsule. This, in turn led to posterior protrusion and swelling of lens tissue. In the course of the first 3 weeks after birth, globular lens cells began to fill the entire anterior and posterior chambers of the eye. Concomitantly, there was massive overexpression of c-mos RNA in the lens. Whereas this construct has high transforming activity when transfected into NIH-3T3 cells, no hyperplasia or neoplasia have been observed in the affected lenses. Increased expression of c-mos RNA was not confined to the lens of the eye but has been detected in any of several tissues tested.
\end{abstract}

[Key Words: c-mos; transgenic; lens differentiation]

Received July 23, 1987; revised version accepted October 5, 1987.

Proto-oncogenes, the normal cellular equivalents of activated oncogenes, have been studied extensively in tumors and in cultured cells (Bishop 1987). Although much has been learned by studying proto-oncogene activation in these systems, most often early events in tumorigenesis and tumor progression are not accessible for analysis. The transgenic mouse system offers unique possibilities of studying the unlimited range of effects of proto-oncogene expression in the developing mammalian organism. Most of the initial work has centered on the oncogenic potential of a diverse array of oncogene and proto-oncogene constructs in the transgenic mouse. Preneoplastic and neoplastic growth have been observed in tissues that became targets of transgene expression at certain stages of development (for review, see Hanahan 1986; Palmiter and Brinster 1986; Westphal 1987). For example, the oncogenic potential of ras has been tested in acinar cells of the pancreas (Quaife et al. 1987), and that of myc in the mammary gland (Stewart et al. 1984) and in the lymphatic system (Adams et al. 1985).

The mos oncogene was acquired by the acute transforming Moloney murine sarcoma virus (Mo-MSV) (Vande Woude et al. 1987) and is a member of the src kinase family of oncogenes (van Beveren et al. 1981). mos is expressed at low levels in transformed cells (Pap- koff et al. 1982; Wood et al. 1983a,b) and in normal tissues (Propst and Vande Woude 1985; Goldman et al. 1987; Propst et al. 1987). The highest levels of expression, an estimated 10-100 copies of RNA per cell, have been detected in normal testes and ovaries (Propst and Vande Woude 1985; Propst et al. 1987). The low level of mos product expressed in transformed cells would imply that it is very efficient as a transforming gene and high levels of mos product expression correlate with cell toxicity (Papkoff et al. 1982).

Regions have been identified in the c-mos proto-oncogene locus that can prevent activation of transforming potential in cis (Wood et al. 1984; McGeady et al. 1986) and evidence for novel tissue-specific regulation of transcription has also been described (Propst and Vande Woude 1985; Propst et al. 1987) indicating that transcription from the c-mos locus is tightly regulated. The mouse c-mos gene can be activated by a proviral long terminal repeat element (LTR) to transform NIH-3T3 cells efficiently in DNA transfection assays (Blair et al. 1981).

To study the effect of high levels of mos expression in the developing mouse, we have generated three transgenic mouse strains containing the proviral LTR-c-mos construct pTS74 (Blair et al. 1981). This construct lacks 
the c-mos upstream transcription termination sequence (UMS) (Wood et al. 1984; McGeady et al. 1986), but in addition to the LTR promoter/enhancer region (Wood et al. 1983b/ contains the transcription initiation regions utilized in the gonads (Propst et al. 1987).

Based on the high transforming activity of pTS74 in NIH-3T3 cells, we were prepared to see neoplastic growth in tissues expressing this gene. However, none of the mice carrying and expressing the pTS74 gene have so far shown any neoplasia that could be related to transgene expression. Instead, a defect of physiological differentiation processes correlating with mos overexpression occurred in the lens of the eye. Lens fiber differentiation is a well-studied process (Piatigorsky 1987). Perturbations of this process by proto-oncogene overexpression offer a novel approach to study details of proto-oncogene action in terminal differentiation.

\section{Results}

\section{Genotypic characteristics}

Founder mice were derived from one-cell embryos of the inbred strain FVB/N by microinjection of pTS74 plasmid sequences either linearized with SalI or excised as an EcoRI-SalI fragment. In pTS74 (Blair et al. 1981), the LTR of Mo-MSV is inserted into genomic mouse sequences about 500 bp upstream from the c-mos coding region (Fig. 1A). One of the founders was female, the other two were male. All three transmitted the genetic trait to progeny and the genomic DNA of these progeny was subjected to detailed Southern blot analysis. The result is shown in Figure 1B. After EcoRI digestion, the endogenous mouse c-mos sequence is recovered as a $15-\mathrm{kb}$ fragment seen in lane 1 . In addition to this $15-\mathrm{kb}$ band, restriction digests of genomic DNAs of the three transgenic strains (lanes 2, 3, and 4) reveal additional bands that hybridize with the c-mos-specific probe. The pattern observed is unique for each strain, suggesting independent sites of integration in the mouse genome. Lanes 5-9 contain digests with two different restriction enzymes, SacI and HindIII, each of them cutting once in the transgene. The SacI-HindIII fragment of the transgene is shown in lane 9 . In addition to this $1.9-\mathrm{kb}$ band, there is a $2.9-\mathrm{kb}$ band in lanes $5-8$, representing endogenous c-mos sequences. Using the bands of endogenous mos sequences as a reference, we determined that mouse 1 contained one copy and mice 2 and 3 three to four copies of the transgene per haploid genome, respectively.

\section{Phenotypic characteristics}

Changes in secondary lens fiber differentiation All three founder mice and their offspring containing the transgene developed a dominant form of lens opacity that was visible as soon as the animals opened their eyes at day 14 after birth. The trait became more conspicuous in the weeks to follow. Figure 2 displays the eyes of 6month-old progeny of two of the three strains. The eyes
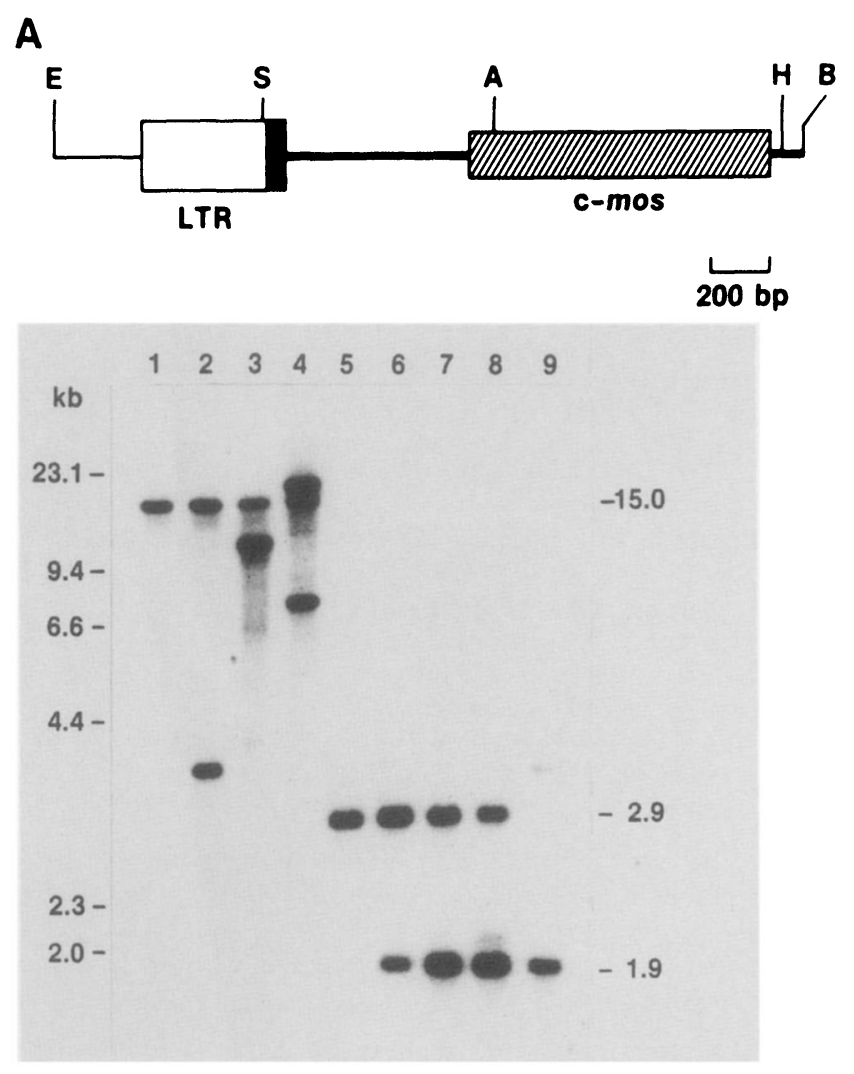

Figure 1. (A) Restriction map of the pTS74 clone (Blair et al. 1981). (ㅁ) Mo-MSV LTR; (solid bar) mouse genomic sequences; (cross-hatched box) c-mos sequences; (thin line) mink genomic sequences. Restriction endonuclease sites are labeled as: $(E)$ EcoRI; (S) SacI; (A) AvaI; (H) HindIII; (B) BamHI-BglII. (B) Restriction enzyme analysis of tail DNA. (Lanes 1-8) $2 \mu \mathrm{g}$ of digested DNA; (lanes 1-4) digestion with EcoRI; (lanes 5-9) digestion with SacI and HindIII; (lanes 1 and 5) normal mouse DNA; (lanes 2 and 6) strain 1 DNA; (lanes 3 and 7) strain 2 DNA; (lanes 4 and 8 ) strain 3 DNA; (lane 9) pTS74 plasmid DNA. Southern analysis followed published procedures (Maniatis et al. 1982). A ${ }^{32} \mathrm{P}$-labeled AvaI-HindIII c-mos fragment $\left(\sim 10^{9} \mathrm{cpm} / \mu \mathrm{g}\right.$ DNA) was used as a probe.

of the transgenic animals (Fig. 2A,C) are shown together with the eye of a wild-type animal of the same strain (Fig. 2B). The intensity of the opacity increased steadily throughout the life of the animals.

Upon examining eyes of young adults of strains 1,2 , and 3 , it was noted that the regular spherical lens was missing and the whole ocular cavity, including the anterior chamber and often the subretinal space, was filled with amorphous gelatinous substances. Stained sections of eyes of a 5-month-old strain 3 transgenic mouse and of a wild-type FVB/N mouse are shown in Figure 3. Histologic examination confirmed that the filling substances were clusters of globular lens cells (Figs. 3A, B). These lens cells in aberrant location were frequently nucleated at the center, and the amorphous cytoplasma was generally well stained with eosin. Many cells were edematous and a few cells were vacuolated (Fig. 3B). Degenerating cells were only found occasionally; elongated lens fiber cells were absent. The rounded lens cells 


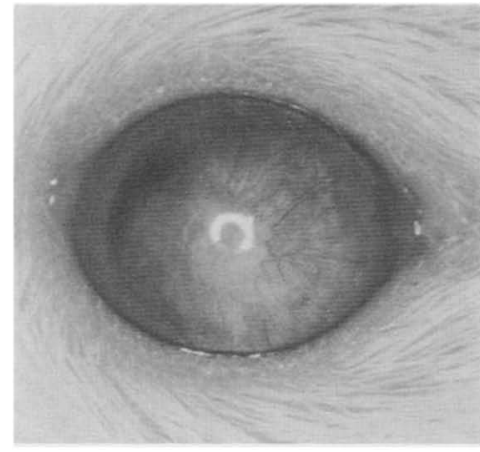

A
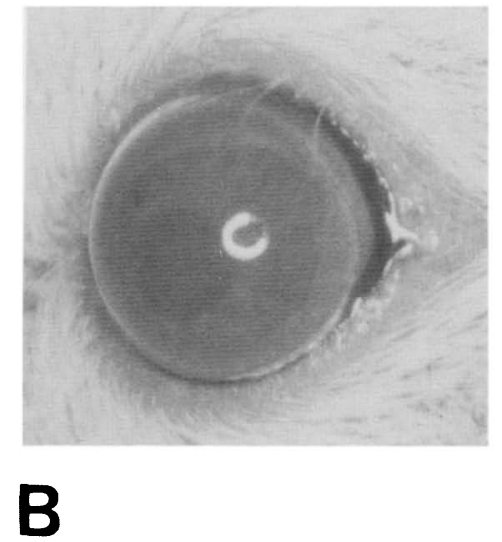
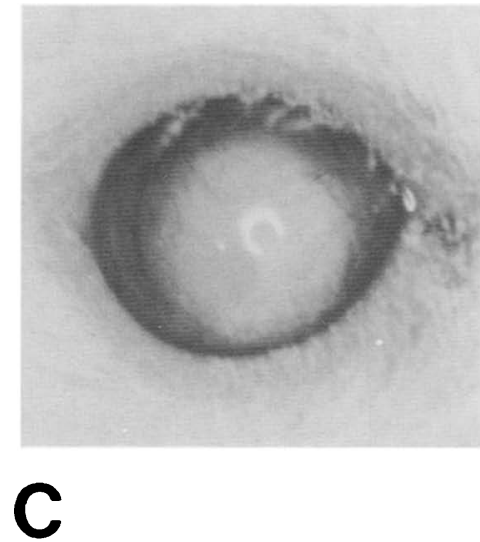

Figure 2. $(A$ and $C)$ Eyes of 6-month-old animals of strains 1 and 3, respectively. $(B)$ Eye of a wild-type FVB/N mouse of comparable age.

seemed to form random groupings, and no sign of differentiation into fibrous tissue was noted. These cell groupings were not surrounded by the capsule, nor by fibrous tissue. Inflammatory or histiocytic reaction was usually absent.

The lens capsule was found grossly distorted. The posterior capsule was totally absent and thickened lens capsule tissue was found amid the mass of lens substances. Small clusters of lens epithelial cells were present at the inner side of the capsule. These cells were found markedly vacuolated and often separated from the lens materials. There were small bundles of lens fiber cells in the areas encased by the thickened capsule, but many lens cells were globular in shape. The general pattern of histologic changes among these young adult animals of all three strains was strikingly uniform. No neoplastic proliferation of lens cells was noted in any of the animals.

The development of lens pathology was followed in strain 3 from the time of its inception shortly after birth to adulthood. The general appearance and size of the lens were normal until about day 3 after birth. However, anomalies were already evident at this early stage (compare Fig. 4A,B). The number of mitotic figures in the lens epithelium was clearly smaller than in the wild-type control, and the embryonal pattern of cell arrangement persisted at the equator. Fiber cells at the equator seemed to be differentiating but cell nuclei persisted, and the extension of the cell body did not suffice to form the regular bow configuration of lens fibers (Fig. 4B). The newly differentiated fiber cells that had moved only a short distance from the equator formed a convex curve against the lens surface instead of the concave arrangement in normal development (Fig. 4B). The capsule, to which basal ends of these cells attached, was considerably thickened at this stage (Fig. 4C). As the capsule of this portion became profoundly thicker at the later stage, production of the posterior capsule seemed to be extremely slow. The apical ends of these fiber cells appeared swollen and failed to form regular connections with the epithelial cells at the anterior cortex. Lens fibers that had been produced at embryonal stages failed to denucleate and became edematous. Both anterior and posterior suture lines became wider, and small numbers of degenerated cells were often noted in these areas. From day 3 to day 7 after birth, these changes became more conspicuous. After day 7 the capsule produced by the insufficiently elongated cells extended to the posterior zone and thickened nodularly at the end. No new capsule material was deposited at the posterior pole. The embryonal capsule that covered this pole zone was still present but it was markedly attenuated. During the second or third week after birth, breakage of the thin embryonal posterior capsule occurred and lens cells began to slip out of the lens (Fig. 5). As lens cells escaped, the original lens became smaller in size. Large cysts formed at the anterior suture zone and at random locations adjacent to the epithelium. Escaped cells became large and globular in shape, and clusters of these cells filled available spaces in the eye. The slippage of the lens cells appeared to continue as long as supply of cells lasted in the original lens, or until about 3 months of age. The number of epithelial cells and elongated fiber cells in the original lens was found markedly reduced during this period. However, no degeneration or calcification occurred in the shrunken lens. Considerable reduction of lens cells was noted both in the original lens area and in the ocular spaces of eyes of 1- and 2-year-old animals. Remaining cells were larger and less frequently nucleated. Cells in the original lenticular area often formed a spherical conglomeration, which seemed to be sclerotic. Degenerating cells were absent. The thick anterior capsule became more conspicuous, and broken ends of the posterior capsule often formed coils. In addition, clusters of the lens cells were frequently surrounded by newly formed capsular materials. A summary of the histology of lens abnormalities is shown graphically in Figure 6.

mos expression The apparent similarity of lens pathology in all three strains suggested a common cause. Since the transgene used to generate these strains has been shown to express c-mos in cells in tissue culture, 
expression of the gene in various tissues of progeny of each strain was tested. The most profound difference between c-mos expression in transgenic mice and in their wild-type counterparts was detected in the eye. RNA extracted from eyes of transgenic animals and of wild-type animals is displayed in a Northern analysis (Fig. 7). Confirming previous analyses, the endogenous transcript is seen in the testis and forms a band at $1.7 \mathrm{~kb}$. However, there is high expression of c-mos RNA in the eyes of transgenic mice, whereas no expression is detectable in the wild-type control (compare lanes 4 and 1). The transcripts from similar LTR-c-mos constructs in trans- formed cells have been shown to be complex (Blair et al. 1981) and this has been attributed to the acquisition of novel poly(A) addition sites (Wood et al. 1983a). Figure 8 shows additional results obtained with an S1 nuclease protection assay. A 1.6-kb end-labeled fragment containing a 925-bp segment corresponding to the AvaIHindIII portion of the transgene (see Fig. 1) (probe A, Propst and Vande Woude 1985) was used as a probe. This segment is shown to be protected by RNA extracted from a number of tissues of transgenic animals of strain 1. In the wild-type animal (Fig. 8A) only RNA of the testis protects the fragment. In contrast, with the trans-
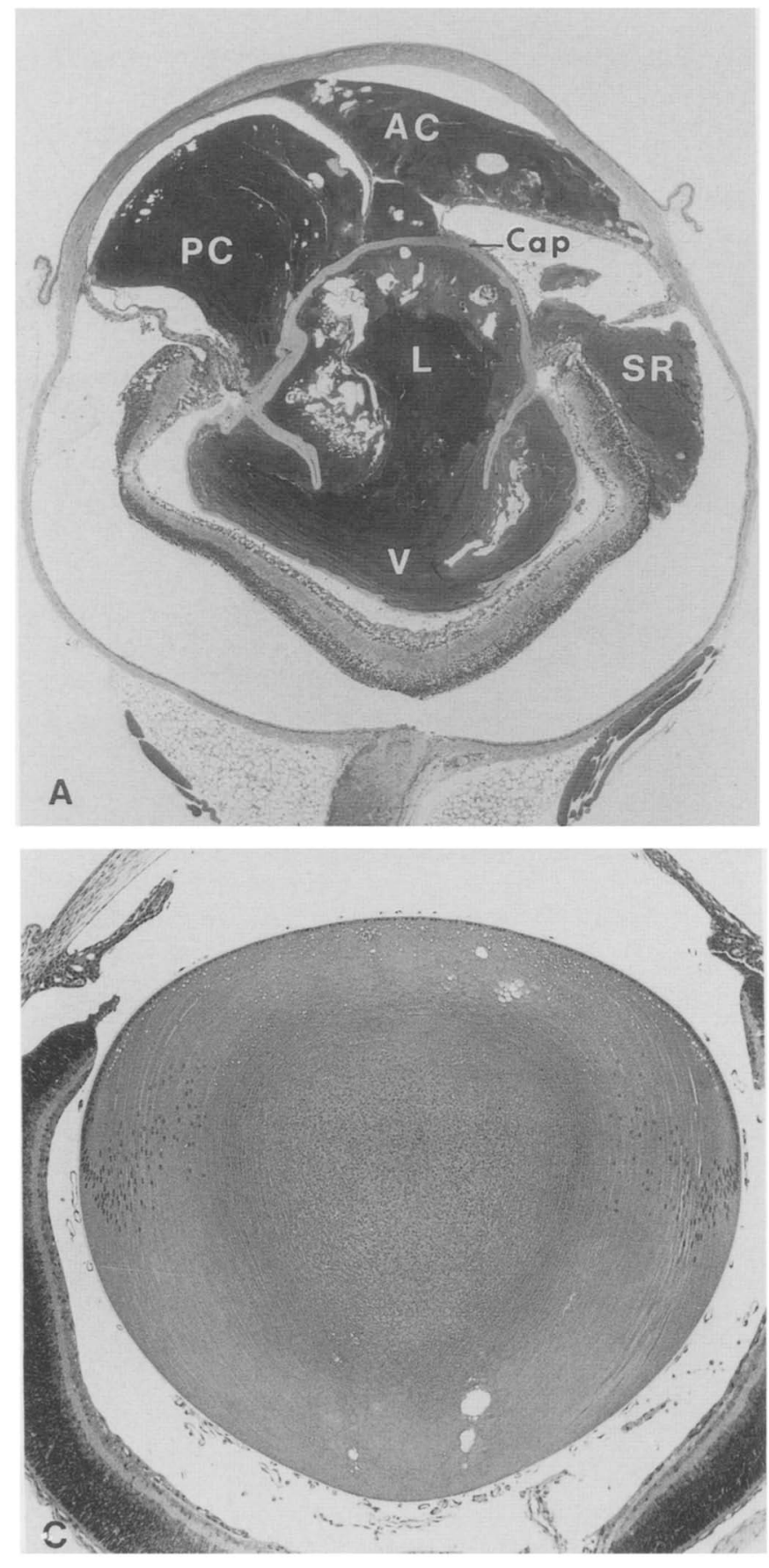

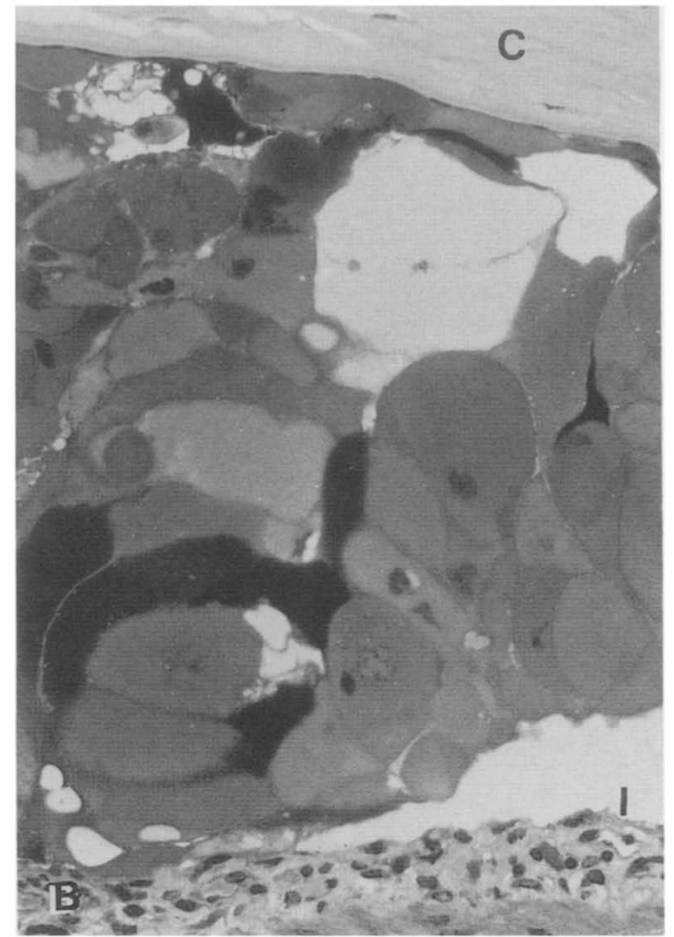

Figure 3. The eyes of a 5-month-old strain 3 transgenic mouse $(A$ and $B \mid$ and of a wild-type $\mathrm{FVB} / \mathrm{N}$ mouse $(C) .(A)$ Lens cells fill the whole ocular cavity: (AC) anterior chamber; $(\mathrm{PC})$ posterior chamber; (SR) subretinal space; (V) vitreous. The small original lens (L) is encased by the thickened anterior capsule (Cap). The posterior capsule is missing. The photoreceptor cell layer is absent due to a retinal degeneration trait found in many inbred strains (Sidman and Green 1965). The retina is artifactually detached. Stain, hematoxylin-eosin; magnification, $25 \times$. (B) Groups of globular lens cells in the anterior chamber. (C) Cornea; (I) iris. Cells are in varying sizes and many are nucleated. Cells are surrounded by the cell membrane. Degenerated cells are darkly stained. Stain, hematoxylin-eosin; magnification, $250 \times$. 

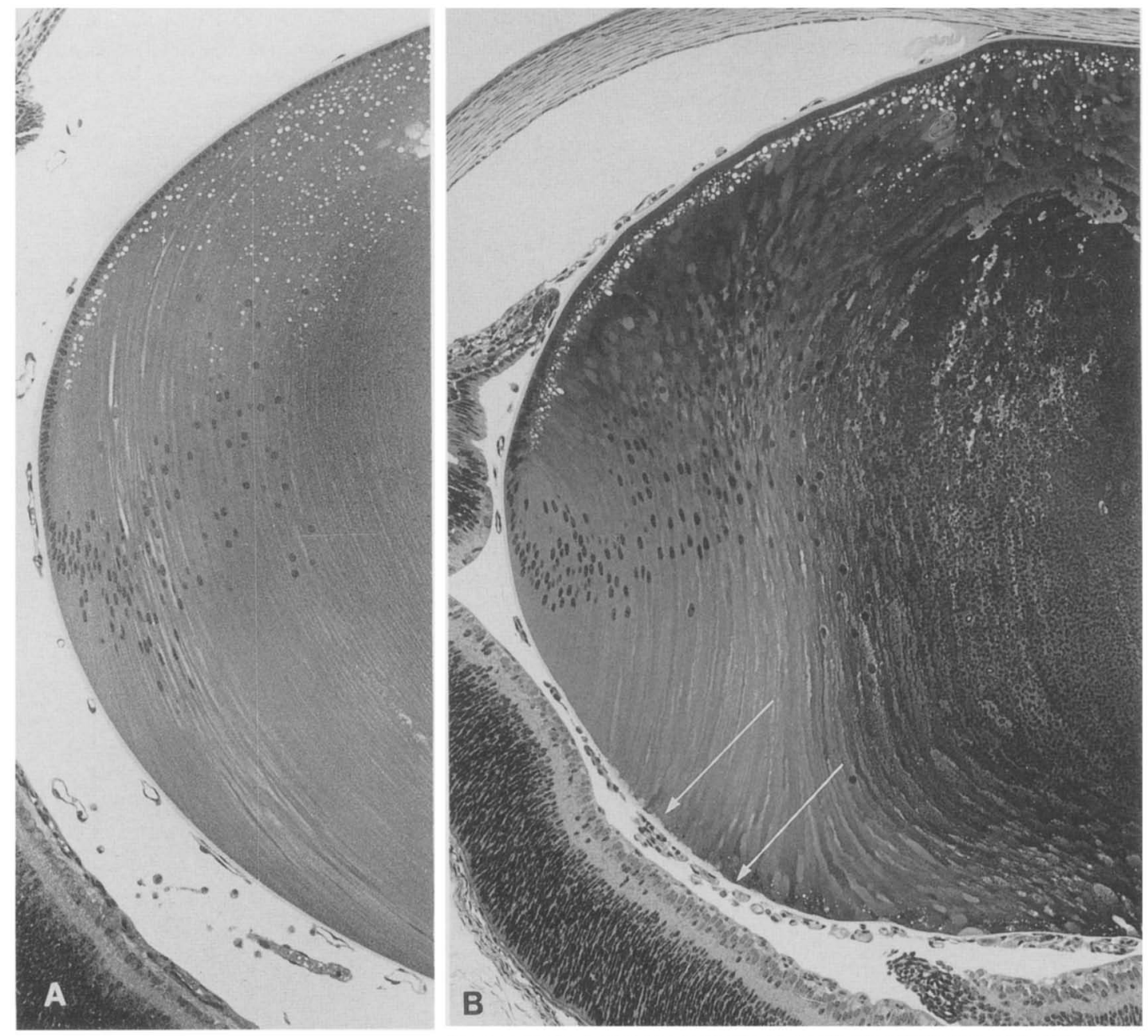

Figure 4. The developing lens of a postnatal 3-day-old strain 3 transgenic mouse $(B$ and $C)$ and of a normal littermate $(A) .(B)$ Insufficiently elongated cells reach only a short distance posterior to the equator (arrows). Lens fibers that have been formed during the embryonal stage are shown on the right. The posterior capsule becomes extremely thin by the second week. Stain, hematoxylin-eosin; magnification, $100 \times .(C)$ The capsule at the area indicated by arrows in $B$ is thickened. Fuzzy PAS staining substances are formed by the insufficiently elongated bow cells. Stain, PAS-; magnification,

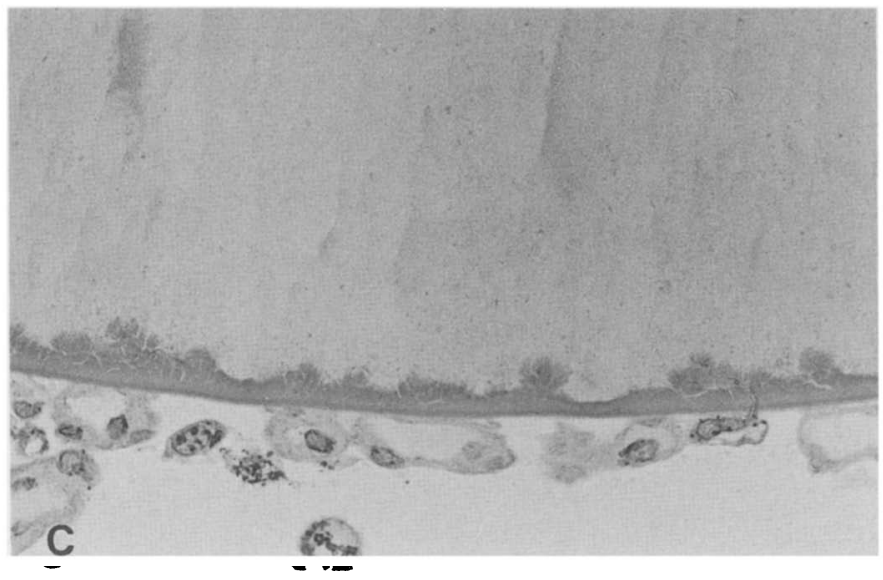
$400 \times$.

genic animal (Fig. 8B), the main protection is obtained as expected from RNA of the eye, but also from RNA of the testis, brain, spleen, and kidney. There is clearly more RNA protecting this fragment in the testis of the transgenic animal than in the wild-type counterpart. An increase in the steady-state levels of RNA encoding the c-mos coding sequence is thus found in a number of organs, suggesting that expression is widespread throughout the body. It was confirmed independently (not shown) that at least the bulk, and possibly all, of the mos RNA detected in the eye was actually located in the lens.

The protein composition of lenses of transgenic animals and their wild-type littermates was determined to examine whether the observed pathology correlated with changes in the production of individual protein components. Lens extracts (Carper et al. 1985) were obtained from animals of different strains and different 


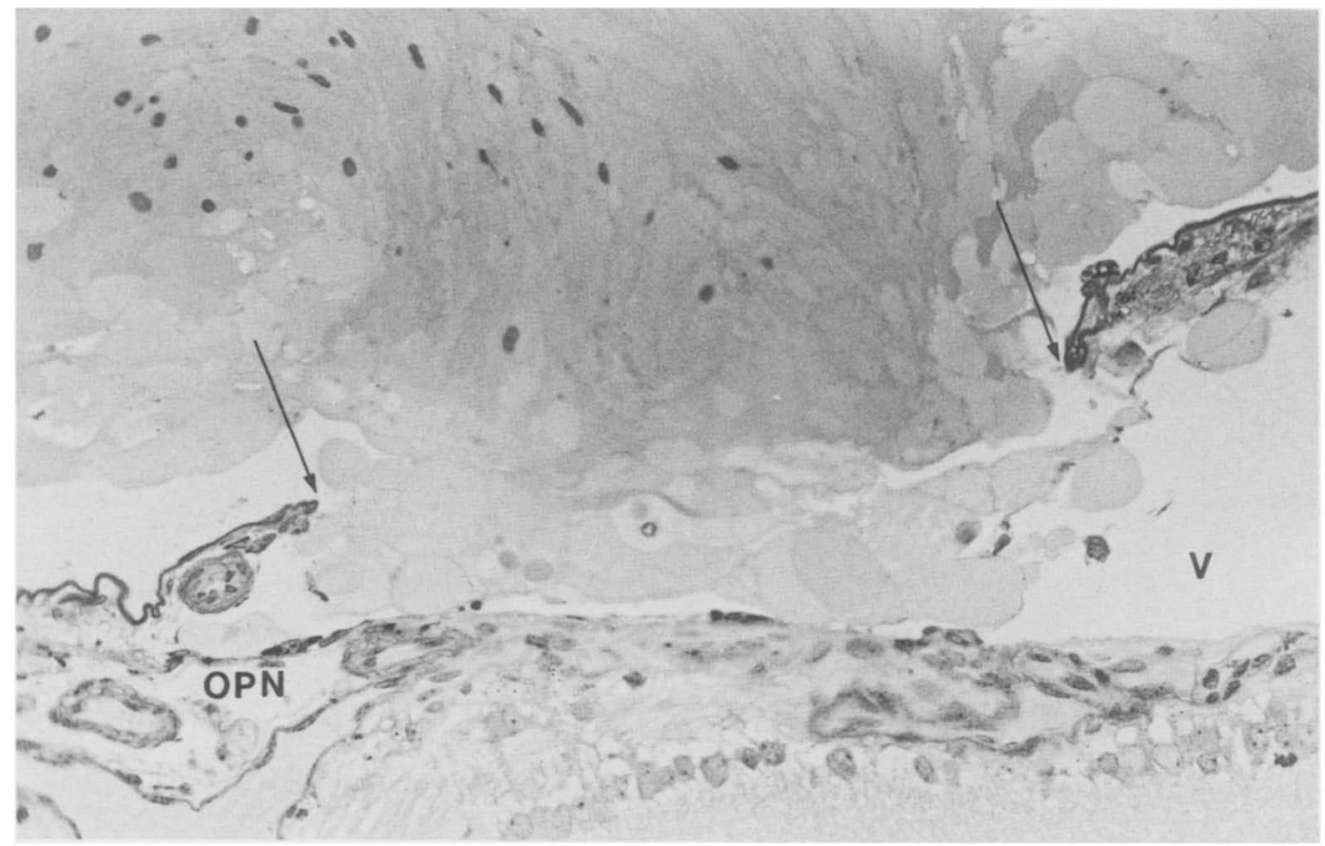

Figure 5. The posterior pole of a 3-week-old strain 3 transgenic mouse lens. The attenuated posterior capsule is broken and coiled (arrows). Lens fiber cells are escaping into the vitreal cavity (V). (OPN) Optic nerve head. Stain, PAS-; magnification, $250 \times$.

Figure 6. Schematic drawing to summarize histologic findings on lenses of all three strains. In the normal mouse, lens fibers are formed by differentiation of epithelial cells at the equator. Nuclei of concentrically elongating cells form the "bow" configuration. Abnormality of the transgenic lens becomes apparent on the third postnatal day. The basal ends of the fiber cells extend only a short distance from the equator. The capsule in this area becomes thickened. The posterior capsule is not formed beyond this zone. By 2-4 weeks, the attenuated posterior capsule ruptures and lens fiber cells escape into the vitreal cavity. Lens fiber cells become globular in shape. Epithelial cells remain present and newly formed fiber cells are occasionally recognizable. By 3-5 months, the anterior capsule becomes very thick and the whole eye cavity, including anterior chamber and subretinal space, fills with globular lens cells.
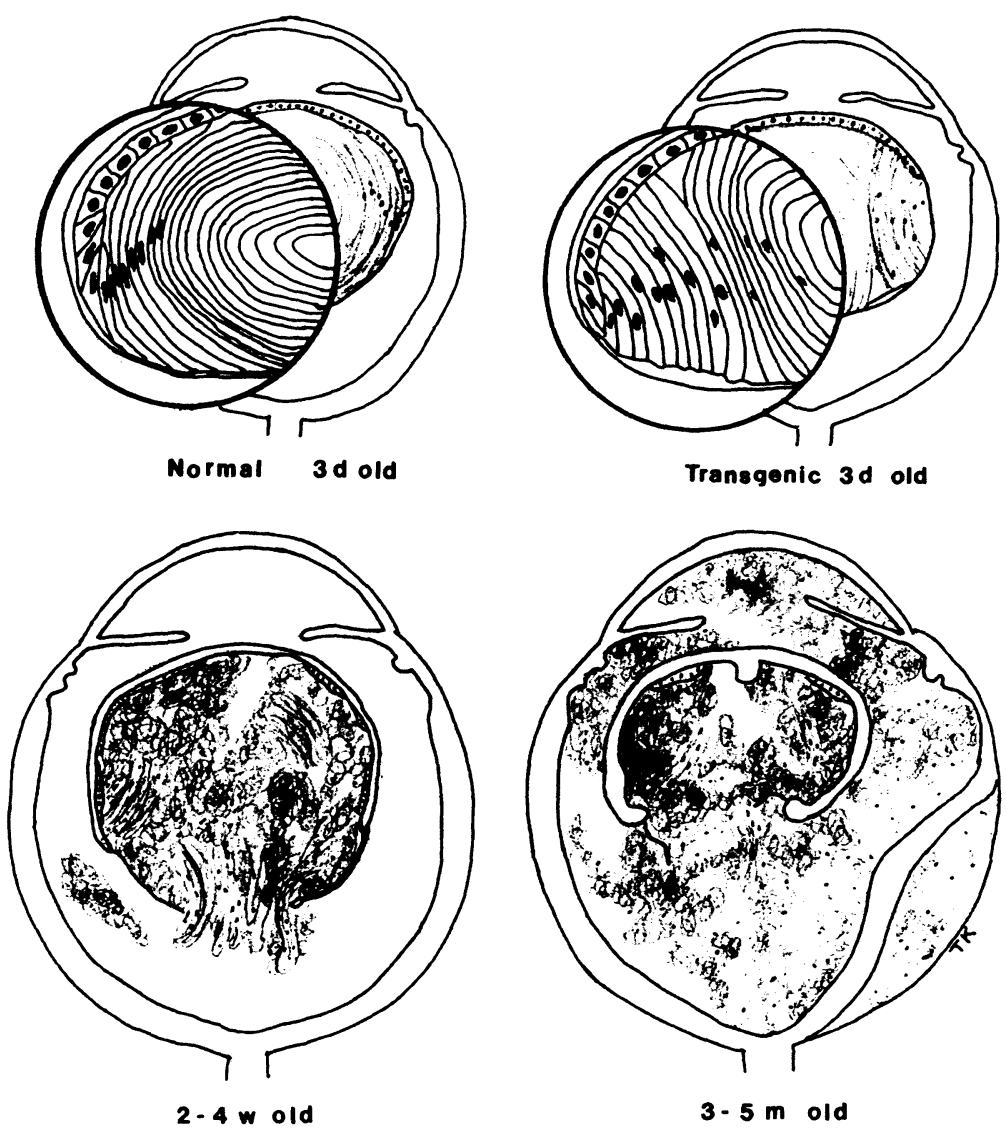

$3.5 \mathrm{~m}$ old 


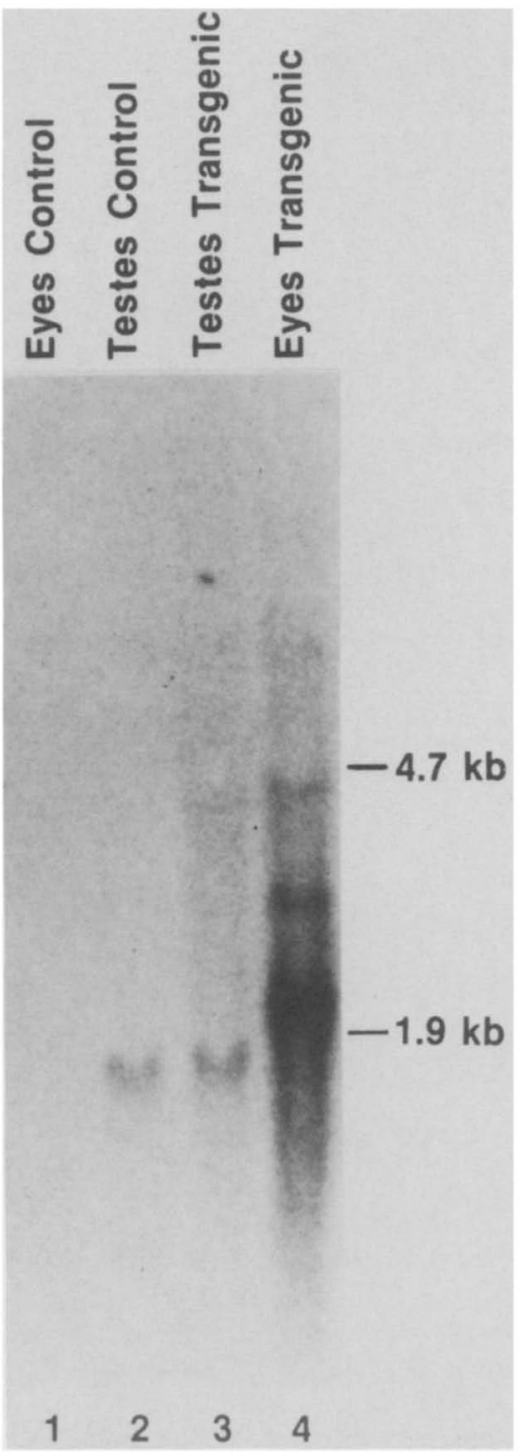

Figure 7. Northern blot analysis: Total RNA $(25 \mu \mathrm{g})$ from testes and eyes was isolated as described in Materials and methods from 5-month-old wild-type (lanes 1-2) or strain 3 transgenic mice (lane 3-4). (Lanes 1 and 4) Eye RNA; (lanes 2 and 3) testis RNA.

ages and compared to wild-type in an isoelectric focusing gel. Neither qualitative nor quantitative differences could be detected (data not shown).

\section{Discussion}

The lens pathology may be summarized as a process that involves defects in secondary lens fiber differentiation and in lens capsule synthesis observed after birth. Breakdown of the capsule at the posterior pole releases grossly distorted lens fiber cells that ultimately fill both chambers of the eye in the adult animal. Although rupture of the posterior capsule and protrusion of lens material through the rupture have been observed before in mutant strains of mice (Fraser and Herer 1950; Beasley
1963|, our findings represent a novel phenotype and suggest a close causative connection between changes in secondary fiber differentiation and the events that precede and follow capsule breakdown. Moreover, they coincide with the overexpression of a well-studied protooncogene. We can, therefore, begin to ask how a given proto-oncogene can interfere with (1) elongation, spatial orientation, and denucleation of the fiber cell and (2) capsule secretion by epithelia and fibers, each of which we find defective in our three transgenic strains. While there is no evidence that mos itself has a physiological role in these processes, our findings nonetheless indicate that mos can influence factors governing lens differentiation. It is possible that the primary target of mos is the equatorial lens epithelia. A decrease in proliferation of these cells not only explains the observed lack of hyperplasia but may actually initiate the chain of events culminating in the observed lens pathology. Studies of proto-oncogene-mediated impairment of differentiation processes in the lens hold the promise of constituting a useful corollary to research aimed at the neoplastic potential of this class of genes in the transgenic mouse. In this context, we would like to point out a recent study by Rüther et al. (1987) that reports on anomalies in bone development in mice overexpressing a c-fos transgene.

The disturbance of physiological processes of differentiation by proto-oncogene overexpression may merely be the initial step of oncogenesis (for review, see Bishop 1987; Palmiter and Brinster 1986; Hanahan 1986; Westphal 1987). There has been a recent demonstration that activation of the c-Ha-ras proto-oncogene by point mutation drastically increases the predisposition of transgenic mice to cancer (Quaife et al. 1987). Activation of a proto-oncogene can also occur by juxtaposition of transcription control elements (Blair et al. 1981). It is all the more remarkable that we do not see any neoplasia in the affected lenses. This is not because the lens is naturally

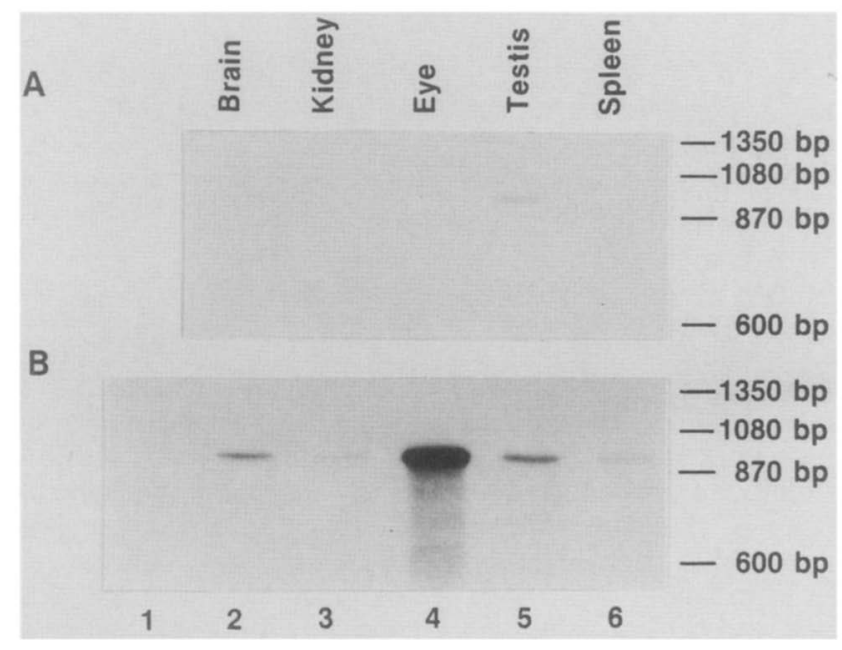

Figure 8. S1 nuclease protection assay. Each lane contains 25 $\mu \mathrm{g}$ of total RNA from wild-type mice $(A)$ or strain 1 transgenic mice 5 months of age $(B)$. (Lane 2) Brain; (lane 3), kidney; (lane 4) eye; (lane 5) testes; (lane 6) spleen; (lane 1) contains $30 \mu \mathrm{g}$ of yeast tRNA. 
refractory to tumor growth. By targeting SV40 tumor antigens to the lens, we have previously shown that lens tumors occur readily in transgenic mice (Mahon et al. 1987). Alternatively, insufficient levels of mos product may be generated at a time of lens development conducive to neoplastic transformation. We have to bear in mind, however, that mos can be a powerful oncogene in vitro (Blair et al. 1981) and in the living mouse (Moloney 1966). Since mos expression is not limited to the lens but has been detected in every tissue tested (Fig. 8), it is possible that in some instances hyperplasias or neoplasias may develop in other parts of the body. Therefore, we keep our animals under continuous surveillance.

The timing and target specificity of pTS74 expression may be mediated by the Mo-MSV LTR. We have previously discussed the fact that related LTR sequences appear to target a variety of tissues of the transgenic animal, starting at or after birth (Overbeek et al. 1986). However, to our knowledge, this is the first example of expression in the intact lens of a gene carrying retroviral LTR sequences. While there may be more of those examples in the future, the sequences downstream of the Mo-MSV LTR in pTS74 should also be viewed in the context of target specificity. We note, for example, that mouse sequences located downstream of the LTR but upstream of mos in pTS74 contain transcription initiation signals utilized in gonadal tissues and possibly in other tissues as well (Propst et al. 1987).

Finally, we observed a phenotype of circular movement in our strains. Since brain is one of the target tissues of mos expression in mice expressing pTS74 (Fig. 8 ), we have begun a detailed study of this phenotype. It is possible that the effect of mos on terminal differentiation of highly specialized cells is far more widespread then our detailed analysis of the lens pathology would suggest.

\section{Materials and methods}

\section{Gene transfer into embryos}

One-cell embryos obtained from an FVB/N $\times \mathrm{FVB} / \mathrm{N}$ cross were microinjected (Brinster et al. 1981). The presence of the transgene in tail DNA of 3-week-old animals was determined by Southern blot analysis (Southern 1975), as described by Khillan et al. (1986).

\section{RNA analysis}

RNA was prepared as described earlier (Propst et al. 1987). For Northern blot analysis, $25 \mu \mathrm{g}$ of total tissue RNA was electrophoresed on agarose-formaldehyde gels and transferred to nitrocellulose paper (Lehrach et al. 1977; Rave et al. 1979; Thomas 1980). The blots were hybridized at $42^{\circ} \mathrm{C}$ in $50 \%$ formamide (Maniatis et al. 1982) using a c-mos-specific fragment (fragment D, described in Propst and Vande Woude 1985) as probe. The film was exposed for 22 days. In preparation for the S1 nuclease protection assay, RNA was annealed with a $1.6-\mathrm{kb}$ DNA fragment (probe A, Propst and Vande Woude 1985) and 3'-end-labeled at the AvaI site at the beginning of the c-mos open reading frame. S1 analysis was carried out following procedures described by Berk et al. (1977) and Favaloro et al. (1980). The film was exposed overnight.

\section{Histologic analysis of the eye}

The eyes of 1-, 3-, 7-, 14-, 21-, 90-, and 150-day-old animals were fixed in $4 \%$ glutaraldehyde in phosphate buffer $(\mathrm{pH} 7.2$ ) for 30 min at room temperature. A small incision was made in the cornea. The eyes were transferred to $10 \%$ formalin and fixed for another $24 \mathrm{hr}$. Vertically oriented central pieces were dissected, dehydrated in ascending concentrations of ethanol, and embedded in glycol methacrylate. From this material, $2-\mu \mathrm{m}$ sections were cut, stained with hematoxylin-eosin and periodic acid Schiff (PAS) reagent, and examined by light microscopy.

\section{Acknowledgments}

We thank Dr. David Beebe, Dr. Donald Blair, Dr. Kathleen Mahon, Dr. Joram Piatigorsky, Dr. Paul Russell, and Dr. Peggy Zelenka for their interest in this work and for helpful suggestions, and Mrs. Kathy Shoobridge for expert care in preparing the manuscript. The research was sponsored, in part, by the National Cancer Institute, DHHS, under Contract No. N01Co-23909 with Bionetics Research, Inc.

\section{References}

Adams, J.M., A.W. Harris, C.A. Pinkert, L.M. Corcoran, W.S. Alexander, S. Cory, R.D. Palmiter, and R.L. Brinster. 1985. The c-myc oncogene driven by immunoglobulin enhancers induces lymphoid malignancy in transgenic mice. Nature 318: $533-538$.

Beasley, A.B. 1963. Inheritance and development of a lens abnormality in the mouse. J. Morphol. 112: 1-11.

Berk, A.J. and P.A. Sharp. 1977. Sizing and mapping of early adenovirus mRNAs by gel electrophoresis of $\mathrm{Sl}$ endonuclease-digested hybrids. Cell 12: 721-732.

Bishop, J.M. 1987. The molecular genetics of cancer. Science 235: 305-311.

Blair, D.G., M. Oskarsson, T.G. Wood, W.L. McClements, P.J. Fischinger, and G.F. Vande Woude. 1981. Activation of the transforming potential of a normal cell sequence: A molecular model for oncogenesis. Science 212: 941-943.

Brinster, R.L., H.Y. Chen, and M.E. Trumbauer. 1981. Mouse oocytes transcribe injected Xenopus 5S RNA gene. Science 211: 396-398.

Carper, D., P. Russell, T. Shinohara, and J.H. Kinoshita. 1985. Differential synthesis of rat lens proteins during development. Exp. Eye Res. 40: 85-94.

Favaloro, J., R. Treisman, and R. Kamen. 1980. Transcription maps of polyoma virus-specific RNA: Analysis by two-dimensional nuclease S1 gel mapping. Methods Enzymol. 65: $718-749$.

Fraser, F.C. and M.L. Herer. 1950. The inheritance and expression of the "Lens Rupture" gene in the house mouse. $I$. Hered. 41: 2-7.

Goldman, D.S., A.A. Kiessling, C.F. Millette, and G.M. Cooper. 1987. Expression of c-mos RNA in germ cells of male and female mice. Proc. Natl. Acad. Sci. 84: 4509-4513.

Hanahan, D. 1986. Oncogenesis in transgenic mice. In Oncogenes and growth control. (ed. T. Graf and P. Kahn), pp. 349-363. Springer-Verlag, Heidelberg.

Khillan, J.S., A. Schmidt, P.A. Overbeek, B. de Crombrugghe, and H. Westphal. 1986. Developmental and tissue-specific expression directed by the $\alpha 2$ type I collagen promoter in transgenic mice. Proc. Natl. Acad. Sci. 83: 725-729.

Lehrach, H., D. Diamond, J.M. Wozney, and H. Boedtker. 1977. RNA molecular weight determinations by gel electrophoresis under denaturing conditions, a critical reexamination. Biochemistry 16: 4743-4751. 
Mahon, K.A., A.B. Chepelinsky, J.S. Khillan, P.A. Overbeek, J. Piatigorsky, and H. Westphal. 1987. Oncogenesis of the lens in transgenic mice. Science 235: 1622-1628.

Maniatis, T., E.F. Fritsch, and J. Sambrook. 1982. Molecular cloning: A laboratory manual. Cold Spring Harbor Laboratory, Cold Spring Harbor, New York.

McGeady, M.L., T.G. Wood, J.V. Maizel, and G.F. Vande Woude. 1986. Sequences upstream from the mouse c-mos oncogene may function as a transcription termination signal. DNA 5: 289-298.

Moloney, J.B. 1966. A virus-induced rhabdomyosarcoma of mice. Natl. Cancer Inst. Monogr. 22: 139-142.

Overbeek, P.A., S.P. Lai, K.R. Van Quill, and H. Westphal. 1986. Tissue-specific expression in transgenic mice of a fused gene containing RSV terminal sequences. Science 235: 15741577.

Palmiter, R.D. and R.L. Brinster. 1986. Germ-line transformation of mice. Annu. Rev. Genet. 20: 465-499.

Papkoff, I., I.M. Verma, and T. Hunter. 1982. Detection of a transforming gene product in cells transformed by Moloney murine sarcoma virus. Cell 29: 417-426.

Piatigorsky, J. 1987. Gene expression and genetic engineering in the lens. Friedenwald lecture. Invest. Opthalmol. Visual Sci. 28: 9-28.

Propst, F. and G.F. Vande Woude. 1985. Expression of c-mos proto-oncogene transcripts in mouse tissues. Nature 315: $516-518$.

Propst, F., M.P. Rosenberg, A. Iyer, K. Kaul, and G.F. Vande Woude. 1987. c-mos proto-oncogene RNA transcripts in mouse tissues: structural features, developmental regulation, and localization in specific cell types. Mol. Cell. Biol. 7: 1629-1637.

Quaife, C.J., C.A. Pinkert, D.M. Ornitz, R.D. Palmiter, and R.L. Brinster. 1987. Pancreatic neoplasia induced by ras expression in acinar cells of transgenic mice. Cell 48: 1023-1034.

Rave, N., R. Crkvenjakov, and H. Boedtker. 1979. Identification of procollagen mRNAs transferred to diazobenzyloxymethyl paper from formaldehyde agarose gels. Nucleic Acids Res. 6: 3559-3567.

Rüther, U., C. Garber, D. Komitowski, R. Müller, and E.F. Wagner. 1987. Deregulated c-fos expression interferes with normal bone development in transgenic mice. Nature 325: 412-416.

Sidman, R.L. and M.C. Green. 1965. Retinal degeneration in the mouse: Location of the $r d$ locus in linkage group XVII. $J$. Hered. 56: 23-29.

Southern, E. 1975. Detection of specific sequences among DNA fragments separated by gel electrophoresis. I. Mol. Biol. 98: $503-517$.

Stewart, T.A., P.K. Pattengale, and P. Leder. 1984. Spontaneous mammary adenocarcinomas in transgenic mice that carry and express MTV/myc fusion genes. Cell 38: 627-637.

Thomas, P.S. 1980. Hybridization of denatured RNA and small DNA fragments transferred to nitrocellulose. Proc. Natl. Acad. Sci. 77: 5201-5205.

van Beveren, C., J.A. Galleshaw, V. Jonas, A.J.M. Berns, R.F. Doolittle, D.J. Donoghue, and I.M. Verma. 1981. Nucleotide sequence and formation of transforming gene of a mouse sarcoma virus. Nature 289: 258-262.

Vande Woude, G.F., M. Oskarsson, M.L. McGeady, A. Seth, F. Propst, M. Schmidt, R. Paules, and D.G. Blair. 1987. In Advances in viral oncology. (ed. G. Klein), vol. 6, pp. 71-81. Raven Press, New York.

Westphal, H. 1987. Transgenic mice. BioEssays 6: 73-76.

Wood, T.G., D.G. Blair, and G.F. Vande Woude. 1983a. Moloney sarcoma virus: Analysis of RNA and DNA structure in cells transformed by subgenomic proviral DNA frag- ments. In Perspectives on genes and the molecular biology of cancer. (ed. D.L. Robberson and G.F. Saunders), pp. 299-306. Raven Press, New York.

Wood, T.G., M.L. McGeady, D.G. Blair, and G.F. Vande Woude. 1983b. Long terminal repeat enhancement of v-mos transforming activity: Identification of essential regions. I. Virol. 46: $726-736$.

Wood, T.G., M.L. McGeady, B.M. Baroudy, D.G. Blair, and G.F. Vande Woude. 1984. Mouse c-mos oncogene activation is prevented by upstream sequence. Proc. Natl. Acad. Sci. 81: 7817-7821. 


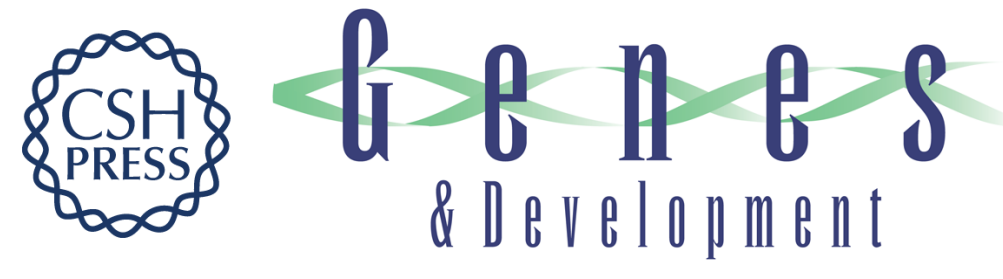

\section{Defects in lens fiber differentiation are linked to c-mos overexpression in transgenic mice.}

J S Khillan, M K Oskarsson, F Propst, et al.

Genes Dev. 1987, 1:

Access the most recent version at doi:10.1101/gad.1.10.1327

References This article cites 32 articles, 11 of which can be accessed free at: http://genesdev.cshlp.org/content/1/10/1327.full.html\#ref-list-1

License

Email Alerting Receive free email alerts when new articles cite this article - sign up in the box at the top Service right corner of the article or click here.

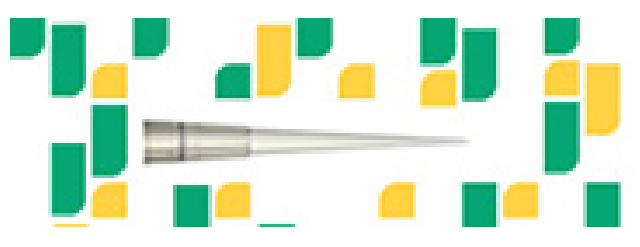

Focused on your science. 